\title{
Epidemiology of Animal Bites and Factors Associated With Delays in Initiating Post-exposure Prophylaxis for Rabies Prevention Among Animal Bite Cases: A Population-based Study
}

\author{
Firooz Esmaeilzadeh ${ }^{1}$, Abdolhalim Rajabi ${ }^{2,3}$, Sajad Vahedi ${ }^{4}$, Mohammad Shamsadiny $^{5}$, Mousa Ghelichi Ghojogh ${ }^{6}$, \\ Nahid Hatam ${ }^{7}$ \\ ${ }^{1}$ Department of Health Economic, School of Nursing and Midwifery, Maragheh University of Medical Sciences, Maragheh; ${ }^{2}$ Department of \\ Epidemiology, Golestan University of Medical Sciences, Gorgan; ${ }^{3}$ Department of Epidemiology, Iran University of Medical Sciences, Tehran; \\ ${ }^{4}$ Department of Health Economic, Student Research Committee, Zabol University of Medical Sciences, Zabol; ${ }^{5}$ Department of Research and \\ Technology, Hormozgan University of Medical Sciences, Bandar E Abbas; ${ }^{6}$ Department of Urima University of Medical Sciences, Urima; \\ ${ }^{7}$ Department of Health Services Management, School of Management and Medical Information, Shiraz University of Medical Sciences, Shiraz, Iran
}

Objectives: One way to prevent deaths due to rabies is the timely utilization of post-exposure prophylaxis (PEP). Therefore, in addition to an understanding of the epidemiological distribution of animal bites, it is necessary to explore the factors leading to delays in PEP initiation.

Methods: This cross-sectional study was conducted in Iran in 2011, and included 7097 cases of animal bites recorded at the Rabies Treatment Center of the Shiraz University of Medical Sciences using the census method. Logistic regression was used to identify factors associated with delays in PEP.

Results: Among the patients studied, 5387 (75.9\%) were males. The prevalence of animal bites in Fars province was 154.4 per 100000 people. Dogs were the most frequent source of exposure (67.1\%), and the most common bitten part of the body was the hands (45.5\%). A delay in the initiation of PEP was found among $6.8 \%$ of the studied subjects. This delay was more likely in housewives (odds ratio [OR], 4.66; 95\% confidence interval [Cl], 2.12 to 10.23 ) and less likely in people with deep wounds (OR, $0.65 ; 95 \% \mathrm{Cl}, 0.43$ to 0.97$)$. Conclusions: Although all animal bite victims received complete PEP, in some cases, there were delays. Further, the type of animal involved, the depth of the bite, and the patient's occupation were the major factors associated with a delay in the initiation of PEP for rabies prevention.

Key words: Post-exposure prophylaxis, Vaccination, Rabies, Delay, Iran

Received: February 15, 2017 Accepted: April 28, 2017

Corresponding author: Abdolhalim Rajabi, PhD

Hemat Highway, Tehran1449614535, Iran

Tel: +98-21-8862-2706, Fax: +98-21-8862-2707

E-mail: rajabiepid@gmail.com

This is an Open Access article distributed under the terms of the Creative Commons Attribution Non-Commercial License (http://creativecommons.org/licenses/by$\mathrm{nc} / 4.0 /$ ) which permits unrestricted non-commercial use, distribution, and reproduction in any medium, provided the original work is properly cited.

\section{INTRODUCTION}

Animal bites are significant causes of morbidity and mortality worldwide, which can be prevented by timely and appropriate post-exposure prophylaxis (PEP) [1]. Studies have suggested that dog bites account for tens of millions of injuries annually [2]. Because rabies is a vaccine-preventable disease, the estimated occurrence of 55000 annual human deaths 
caused by this disease worldwide is unacceptable and inexcusable [3]. Rabies caused by rhabdovirus genotype 1 is one of the most common fatal infections worldwide. It is mainly associated with dog bites in Europe, Asia, and Africa, and with bats in the Americas [4]. Despite the successful prevention of human rabies and control of canine rabies in North America, Western Europe, and a number of Asian and Latin American countries, this disease is considered to be a neglected tropical disease [5]. Rabies is one of the most important viral zoonotic diseases because of its universal distribution [6], the frequency of its outbreaks, its high human and veterinary costs, its high death rate, and the resulting high economic expenditures in different countries of the world every year [7].

The incidence of animal bites in the Islamic Republic of Iran has increased in the recent years. Historically, rabies and animal bites have been present in Iran as endemic health problems [8]. The majority of bites, both national and international, were caused by dogs. However, other animal bites should not be neglected. Therefore, along with the overall health services provided at rural and urban health centers, preventive and curative health programs for rabies are provided.

According to a World Health Organization (WHO) report, to prevent this disease, more than 15 million people receive post-exposure vaccination every year worldwide [3]. In reality, PEP is the most critical life-saving intervention essential for the prevention of rabies in humans after exposure [9].

Post-exposure treatment for suspected rabies exposures in Iran according to the WHO guidelines is as follows: In the first stage, wounds must be immediately washed/flushed for 15 minutes and disinfected, and if the person was bitten by a stray or wild animal, PEP injections should be administered on days $0,3,7,14$, and 28 . However, if the animal was a pet or monitored animal, PEP injection should be administered on days 0,3 , and 7 . If the animal remains healthy 10 days after the bite, the 2 latter injections need not be administered $[10,11]$.

In Iran, rabies has been reported in most provinces. Thus, the management of this disease is considered to be one of the most important priorities of the Iranian health authorities. Therefore, rabies immunization and PEP treatment are provided free of charge in Iran, and almost all people who have been bitten receive PEP [12]. However, delays in receiving PEP can affect the effectiveness of the treatment. Thus, in this study, we investigated the epidemiologic features of animal bites and the factors associated with delays in the initiation of PEP among animal bite cases at an anti-rabies clinic in southwest Iran.

\section{METHODS}

This was a population-based cross-sectional study conducted on all animal bite cases in the Fars province (southwest Iran, with a population of 4596658 [2 315914 males and 2280744 females [13]) between March 2011 and March 2012 (for a duration of 1 year, using the census method). The study was approved by the Ethics Committee of the Shiraz University of Medical Sciences. Data were gathered from all animal bite cases who presented at the Rabies Treatment Center of Shiraz University of Medical Sciences to receive active care. A total of 7097 patients presented at the anti-rabies clinic with a history of an animal bite during the study period. A semi-structured questionnaire was used for collecting information regarding the interval between exposure and the initiation of anti-rabies PEP, the socioeconomic status of the family, the bite site on the body, and other risk factors associated with the delay in the initiation of the vaccine. For the purpose of this study, a delay in the initiation of anti-rabies PEP was defined as the initiation of PEP $\geq 48$ hours after the animal bite [14]. Since the scope of this study was limited to individuals who sought treatment at the Rabies Treatment Center, it is possible that our study excluded some individuals who were bitten but did not seek treatment.

Data were entered into Stata version 12 (StataCorp., College Station, TX, USA) and analyzed. First, variables regarding the distribution of the animal bites were determined. Then, univariate logistic regression was used for determining the risk factors associated with delays in PEP, and we used multiple logistic regression to control for potential confounding factors. $p$-values $<0.05$ were considered to indicate statistical significance.

\section{RESULTS}

During the study period, 7097 animal bite victims (1.54 per 1000 people) presented at the Rabies Treatment Center and were interviewed. Of the victims, 5387 (75.9\%) were males (prevalence of 2.33 per 1000 in the male population) and $24.1 \%$ were females (prevalence of 0.75 per 1000 in the female population) (Table 1). A majority (58.9\%) of the bite victims were younger than 30 years of age. The median age of the studied subjects was 27 years (interquartile range, 18 to 42 years).

Most of the animal bites were from dogs (67.1\%); 37 subjects $(0.5 \%)$ reported to have been bitten by sheep and goats. Further, approximately four-fifths (79.5\%) of the bites were 
Table 1. Animal bites prevalence by age and sex in Fars province in 2012

\begin{tabular}{lccc}
\hline Variables & Population & $\begin{array}{c}\text { No. of subjects } \\
\text { bitten }\end{array}$ & $\begin{array}{c}\text { Prevalence } \\
\text { per 1000 }\end{array}$ \\
\hline Sex & & & \\
Male & 2315914 & 5387 & 2.33 \\
Female & 2280744 & 1710 & 0.75 \\
Age (y) & & & \\
$0-10$ & 691764 & 1039 & 1.50 \\
$11-20$ & 732350 & 1106 & 1.51 \\
$21-30$ & 1103251 & 2027 & 1.84 \\
$31-40$ & 759699 & 1066 & 1.40 \\
$41-50$ & 541231 & 800 & 1.48 \\
$51-60$ & 390475 & 609 & 1.56 \\
$\geq 61$ & 374647 & 442 & 1.18 \\
\hline
\end{tabular}

from pets, while 1053 (15.8\%) were from stray animals (Table 2).

A majority (85.9\%) of those who presented at the Rabies Treatment Center came within 24 hours of the animal bite. A delay (of $\geq 48$ hours) in the initiation of PEP was observed in $6.8 \%$ of the animal bite patients. Table 1 presents the epidemiologic characteristics of the bitten subjects and the various factors associated with a delay in the initiation of PEP.

We found that certain occupational groups, such as farmers, students, housewives, and entrepreneurs, were significantly more likely to delay PEP than employees. Likewise, among the victims, those bitten by monkeys and cows (odds ratio [OR], 4.67; 95\% confidence interval [Cl], 1.42 to 15.30) and sheep and goats (OR, $6.97 ; 95 \% \mathrm{Cl}, 2.21$ to 21.99$)$ were more at risk of delaying PEP than those bitten by dogs. Further, deeper bites were inversely associated with a delay in PEP (OR, 0.65; 95\% $\mathrm{Cl}, 0.43$ to 0.97$)$. A delay in the initiation of anti-rabies PEP was not significantly related to the age group, type of animal, site of the bite, or sex of the subject (Table 2).

\section{DISCUSSION}

Animal bites are an important cause of mortality throughout the world and present a major public health problem in Iran [15]. Therefore, the present study was designed with the aim of investigating the characteristics of animal bite victims in Fars province (in southwest Iran), their geographic distribution, and the factors associated with delays in anti-rabies treatment. The results of this study show that the distribution of animal bites differed according to certain characteristics of the victims. Further, an investigation of the factors adversely affecting timely anti-rabies treatment showed that the victim's occupation, the depth of the wound, and the type of animal involved were related to delays in treatment.

The present study showed that during the study period, 7097 cases of animal bites (prevalence of 154.4 in 100 000) were reported. Another study carried out in one of the provinces in southwest Iran (Ahvaz province) showed that 4184 cases of animal bites were reported between 2003 and 2007 [16]. Furthermore, the study by Dadypour et al. [17] on the incidence rate of animal bites in the city of Kalaleh indicated that 745787 , and 788 cases of animal bites were reported per 100 000 people in the years 2003, 2004, and 2005, respectively, with an average of 773 cases per 100000 . Another study in Switzerland in 1998 reported an incidence of 235 animal bites per 100000 people [18]. Therefore, we can infer that the results of some of the studies conducted in different areas, such as the Ahvaz province, were consistent with those of the present study, whereas our findings are inconsistent with those of other studies, most likely due to differing risks of animal bites. In the present study, most animal bites occurred in males (75.9\%). That is, the incidence of animal bites in males was approximately three times higher than was observed in females. In a study by Khazaei et al. [19], animal bites were likewise most often observed in males (71.8\%) [19]. Further, a study carried out in France reported the sex ratio of animal bites (male-to-female) to be 1.98 [20], and a study by Joseph et al. [14] confirmed this result. This correlation is consistent with the results of the present study. The higher prevalence of animal bites in males than in females can be attributed to their more frequent exposure, conscious risk-taking, and the larger amount of time spent outside the home. In contrast, a study by Pandey et al. [21] on tourists and foreigners in Nepal showed that the incidence of animal bites was higher in females than in males; these results reinforce the likelihood of suffering from animal bites outside the home.

A majority of the studies conducted in different countries have shown that most animal bites, particularly dog bites, were suffered by children [20,22]; the present study also revealed that most of the victims were young people in the age range of 11 to 30 years (44.2\%) who were away from home and were bitten by pets. This result is consistent with the results of most studies conducted across the world [16,17,20,22,23].

The present study found that most victims of animal bites were self-employed (36.1\%), while Kassiri et al. [23] reported 
Table 2. Distribution of demographic and clinical characteristics of the bitten subjects, delays in the initiation of anti-rabies vaccination, and the factors associated with delays among animal bite patients, 2012 ( $n=7097)$

\begin{tabular}{|c|c|c|c|c|c|c|c|}
\hline \multirow{2}{*}{ Factors for delay } & \multirow{2}{*}{ Total } & \multicolumn{2}{|c|}{ Delay } & \multicolumn{2}{|c|}{ Unadjusted analysis } & \multicolumn{2}{|c|}{ Adjusted analysis } \\
\hline & & Present & Absent & OR $(95 \% \mathrm{CI})$ & $p$-value & OR (95\% Cl) & $p$-value \\
\hline \multicolumn{8}{|l|}{ Sex } \\
\hline Male & $5387(75.9)$ & $326(6.1)$ & 5044 (93.9) & Reference & & Reference & \\
\hline Female & $1710(24.1)$ & $155(9.1)$ & $1549(90.9)$ & $1.54(1.26,1.89)$ & $<0.001$ & $0.92(0.56,1.52)$ & 0.76 \\
\hline \multicolumn{8}{|l|}{ Age $(y)^{1}$} \\
\hline $0-10$ & $1039(14.7)$ & $64(6.2)$ & 973 (93.8) & Reference & & N/A & \\
\hline $11-20$ & $1106(15.6)$ & $79(7.2)$ & 1022 (92.8) & $1.17(0.83,1.65)$ & 0.35 & N/A & \\
\hline $21-30$ & 2027 (28.6) & $135(6.7)$ & 1886 (93.3) & $1.08(0.80,1.48)$ & 0.59 & N/A & \\
\hline $31-40$ & 1066 (15) & $79(7.4)$ & 985 (92.6) & $1.21(0.86,1.71)$ & 0.25 & N/A & \\
\hline $41-50$ & $800(11.3)$ & $52(6.5)$ & $746(93.5)$ & $1.06(0.72,1.54)$ & 0.76 & N/A & \\
\hline $51-60$ & 609 (8.6) & $35(5.8)$ & $571(94.2)$ & $0.93(0.60,1.42)$ & 0.74 & N/A & \\
\hline$\geq 61$ & 442 (6.2) & $37(8.4)$ & 402 (91.6) & $1.39(0.91,2.13)$ & 0.11 & N/A & \\
\hline \multicolumn{8}{|l|}{ Occupation of patients } \\
\hline Employee & 487 (9.0) & $16(3.3)$ & $471(96.7)$ & Reference & & Reference & \\
\hline Farmer & $440(8.1)$ & $30(6.8)$ & 409 (93.2) & $2.15(1.16,4.01)$ & 0.01 & $2.31(1.05,5.10)$ & 0.03 \\
\hline Animal husbandry & $298(5.5)$ & $22(7.4)$ & $276(92.6)$ & $2.34(1.21,4.54)$ & 0.01 & $1.90(0.80,4.55)$ & 0.14 \\
\hline Housewife & $912(16.8)$ & $105(11.6)$ & $802(88.4)$ & $3.85(2.25,6.60)$ & $<0.001$ & $4.66(2.12,10.23)$ & $<0.001$ \\
\hline Student & $1340(24.6)$ & $96(7.2)$ & 1239 (92.8) & $2.28(1.32,3.91)$ & 0.003 & $2.13(1.07,4.24)$ & 0.03 \\
\hline Entrepreneur/self-employed & $1963(36.1)$ & $117(6.0)$ & $1839(94.0)$ & $1.87(1.10,3.18)$ & 0.02 & $1.97(1.03,3.87)$ & 0.04 \\
\hline \multicolumn{8}{|l|}{ Type of animal } \\
\hline Wild & $311(4.7)$ & $17(5.5)$ & $294(94.5)$ & Reference & & Reference & \\
\hline Pet & $5302(79.5)$ & $374(7.1)$ & 4915 (92.9) & $1.31(0.79,2.17)$ & 0.28 & $1.66(0.71,3.87)$ & 0.23 \\
\hline Stray & $1053(15.8)$ & $62(5.9)$ & $985(94.1)$ & $1.08(0.62,1.89)$ & 0.76 & $1.83(0.76,4.36)$ & 0.17 \\
\hline \multicolumn{8}{|l|}{ Animal status } \\
\hline $\begin{array}{l}\text { Healthy throughout the 10-day } \\
\text { period of observation }\end{array}$ & 4305 (75.2) & $296(6.9)$ & 3996 (93.1) & $0.68(0.42,1.11)$ & 0.13 & $0.60(0.30,1.23)$ & 0.16 \\
\hline Escaped & 1226 (21.4) & $69(5.7)$ & 1152 (94.3) & $0.55(0.32,0.94)$ & 0.03 & $0.51(0.24,1.08)$ & 0.08 \\
\hline Killed & $196(3.4)$ & $19(9.7)$ & $176(90.3)$ & Reference & & Reference & \\
\hline \multicolumn{8}{|l|}{ Bite site } \\
\hline Head and neck & $200(2.9)$ & $16(8.0)$ & $184(92.0)$ & $2.32(1.06,5.38)$ & 0.04 & $2.07(0.51,8.25)$ & 0.30 \\
\hline Trunk & 185 (2.7) & $10(5.4)$ & 174 (94.6) & $1.53(0.61,3.86)$ & 0.35 & $1.40(0.39,5.04)$ & 0.60 \\
\hline Hands & 3148 (45.5) & $217(6.9)$ & 2919 (93.1) & $1.99(1.08,3.92)$ & 0.04 & $1.82(0.64,5.16)$ & 0.25 \\
\hline Lower limbs & 3139 (45.3) & $219(7.0)$ & 2913 (93.0) & $2.01(1.02,3.97)$ & 0.04 & $2.02(0.71,5.73)$ & 0.18 \\
\hline Not documented & 250 (3.6) & $9(3.6)$ & 241 (96.4) & Reference & & Reference & \\
\hline \multicolumn{8}{|l|}{ Depth of bite } \\
\hline Surface & 5508 (84.1) & $398(7.2)$ & 5093 (92.8) & Reference & & Reference & \\
\hline Deep & 1045 (15.9) & $49(4.7)$ & 993 (95.3) & $0.63(0.46-0.85)$ & 0.003 & $0.65(0.43,0.97)$ & 0.03 \\
\hline \multicolumn{8}{|l|}{ Animals } \\
\hline Dog & $4725(67.1)$ & $296(6.3)$ & 4420 (93.7) & Reference & & Reference & \\
\hline Cat & 1728 (24.5) & $119(6.9)$ & 1602 (93.1) & $1.06(0.85,1.33)$ & 0.55 & $0.85(0.59,1.24)$ & 0.42 \\
\hline Wolf or fox & $56(0.8)$ & $4(7.1)$ & 52 (92.9) & $1.16(0.41,3.24)$ & 0.29 & $0.69(0.08,5.91)$ & 0.73 \\
\hline Monkey or cow & $39(0.5)$ & $6(15.4)$ & 33 (84.6) & $2.81(1.16,6.79)$ & 0.02 & $4.67(1.42,15.30)$ & 0.01 \\
\hline Mouse & $128(1.8)$ & $9(7.0)$ & $119(93.0)$ & $1.09(0.55,2.18)$ & 0.78 & $1.60(0.48,5.31)$ & 0.44 \\
\hline Sheep or goat & $37(0.5)$ & $9(28.1)$ & 23 (71.9) & $5.68(2.60,12.4)$ & $<0.001$ & $6.97(2.21,21.99)$ & 0.001 \\
\hline Other & $332(4.7)$ & $37(11.2)$ & $293(88.8)$ & $1.87(1.30,2.69)$ & 0.001 & $2.20(1.28,3.77)$ & 0.004 \\
\hline
\end{tabular}

Values are presented as number (\%).

OR, odds ratio; $\mathrm{Cl}$, confidence interval; N/A, not applicable.

'Because the variables were not significant in the unadjusted form or had a $p$-value of $>0.20$; they were not included in the adjusted model. 
that the highest incidence of animal bites was among students (28.9\%). In addition, several studies, including those by previous studies $[17,24,25]$ showed that the greatest incidence of animal bites was among students. This is not consistent with the results of the present study. The reason for this difference is probably the methodology of assessing the occupational status of animal bite victims.

This study showed that the parts of the body most commonly injured by animal bites were the lower limbs (45.3\%) and the hands (45.5\%). In previous studies [16,24], the highest rate of injury was observed in the lower parts of the body and the legs; this is consistent with the results of our study. Moreover, the present study showed that most cases of animal bites involved superficial injuries (84.1\%). In the study by Poorolajal et al. [26], too, the rate of superficial injuries was high (79.0\%); this is consistent with the results of our study. In the present study, dogs (67.1\%) were most commonly responsible for animal bites, and the results of a majority of related studies are consistent with those of the present study in this regard $[14,17-19,23,24]$. This may be attributed to the presence of dogs in most rural houses.

Rabies PEP is essential for the prevention of this fatal disease. However, many factors influence timely access to PEP and its administration. Therefore, in this study, we investigated factors affecting delays in receiving anti-rabies PEP.

With the introduction of the anti-rabies vaccine, access to PEP and efforts to administer it have increased $[27,28]$. Despite the efforts of the governments to provide animal bite victims with free rabies vaccines, some deaths caused by rabies are still reported in different countries [29,30]. Most of these deaths occur in rural areas and among males and children under 15 years of age [31,32].

In the present study, $6.8 \%$ of animal bite victims did not receive timely PEP treatment, but findings of national and international studies are contrary to this; in several other studies, 15 to $67 \%$ of the patients did not seek medical services or did not receive any PEP $[14,19,33,34]$. The probable reason for the difference in delay compared to other countries is that in Iran, anti-rabies healthcare is provided actively and people are highly sensitive to rabies. However, the reason for the difference between the results of a study by Khazaei et al. [19] and the present study is the different definition of a delay $(<6$ hours was considered timely treatment in their study).

In our study, we indicated that in the multiple logistic regression analysis, age groups did not have a significant effect on PEP treatment; this is consistent with the findings of Khazaei et al. [19]. However, results of the study by Joseph et al. [14] were contrary to the results of our study; this difference may be attributed to different analytical techniques. Specifically, in that study, potential confounders were not controlled for.

Our study showed that among occupational groups, housewives had the highest rate of delay in receiving PEP, with a risk 4.66 times greater than was observed among employees. This indicates the need for increased awareness among housewives about the timely reception of PEP.

Our study showed that deep wounds (The open wound and excessive bleeding.) caused by animal bites were inversely associated with delays in PEP; in the case of deep wounds, a $35.0 \%$ reduction was found in the risk of delay. The reason for this finding is obvious: people who have deep wounds will visit health centers as soon as possible and receive anti-rabies treatment care. Our study showed that $15.9 \%$ of the wounds treated were deep, among which a delay occurred in only $4.7 \%$. The results of the other studies [14.19.35] are consistent with those of our study.

Finally, this study showed a significant relationship between the type of animal involved and delays in receiving PEP. Bites by dogs (the most frequent cause of animal bites) had a $6.3 \%$ delay in PEP, while bites by goats and sheep had a $28.1 \%$ delay. This difference may be related to the sensitivity and the depth of the injuries caused by dogs. The results of the study by Khazaei et al. [19] as well as those reported by Riahi et al. [36] are consistent with the results of the present study.

Considering that PEP is provided only in certain selected health centers in Iran, another policy to reduce the delay time is to increase the number of centers providing PEP services. These centers should be located in such a way that the travel time from the villages and the residential areas to these service providers does not exceed a specified amount of time, (with the maximum allowable time to be determined by a collaborative examination of the relevant literature).

Since this study was designed as a population-based study, it can be easily generalized to the population in question, and the intended interventions can be applied to this population in order to increase the timely reception of PEP. This is one of the main advantages of our study. However, the present study was retrospective and we did not have access to data on the economic status of the victims of animal bites, the seasonality of biting, and the distance between the victims and anti-rabies medical centers. Therefore, these factors can be regarded as 
limitations of the present study.

This study provides relevant information about animal bites in humans, the risk factors associated with animal bites, and various aspects of receiving PEP services. It demonstrated that the occupational group most likely to experience delays in PEP is housewives. This group consists of females; therefore, more attention has to be paid to this group. Further, delays were significantly associated with being bitten by ruminants; this shows that the injuries caused by this group of animals do not receive appropriate attention. Hence, we need to provide appropriate training and information in this regard in order to ensure timely PEP treatment.

\section{CONFLICT OF INTEREST}

The authors have no conflicts of interest associated with the material presented in this paper.

\section{ORCID}

Firooz Esmaeilzadeh http://orcid.org/0000-0002-7068-5688

Abdolhalim Rajabi http://orcid.org/0000-0002-0698-8166

Sajad Vahedi http://orcid.org/0000-0002-5698-0699

Mohammad Shamsadiny http://orcid.org/0000-0001-62775651

Mousa Ghelichi Ghojogh http://orcid.org/0000-0002-07265509

Nahid Hatam http://orcid.org/00000001-7738-1970

\section{REFERENCES}

1. Franka R, Wu X, Jackson FR, Velasco-Villa A, Palmer DP, Henderson $\mathrm{H}$, et al. Rabies virus pathogenesis in relationship to intervention with inactivated and attenuated rabies vaccines. Vaccine 2009;27(51):7149-7155.

2. World Health Organization. Animal bites; 2013 [cited 2017 Apr 29]. Available from: http://www.who.int/mediacentre/ factsheets/fs373/en/.

3. World Health Organization. Rabies; 2017 [cited 2017 Apr 30]. Available from: http://www.who.int/mediacentre/factsheets/ fs099/en/.

4. Hemachudha T, Ugolini G, Wacharapluesadee S, Sungkarat W, Shuangshoti S, Laothamatas J. Human rabies: neuropathogenesis, diagnosis, and management. Lancet Neurol 2013; 12(5):498-513.
5. World Health Organization. Investing to overcome the global impact of neglected tropical diseases: third WHO report on neglected diseases 2015 [cited 2017 Apr 30]. Available from: http://apps.who.int/iris/bitstream/10665/152781/1/978924 1564861_eng.pdf.

6. Esmaeilzadeh F, Hatam N, Esmaeilzadeh Z, Rajabi A, Anami M, Vahedi $S$, et al. Effectiveness of post-exposure rabies prophylaxis. Tehran Univ Med J 2014;72(9):630-637 (Persian).

7. Hatam N, Esmaelzade F, Mirahmadizadeh A, Keshavarz K, Rajabi A, Afsar Kazerooni $P$, et al. Cost-effectiveness of rabies post exposure prophylaxis in Iran. J Res Health Sci 2014;14(2): 122-127.

8. Dalfardi B, Esnaashary MH, Yarmohammadi H. Rabies in medieval Persian literature: the Canon of Avicenna (980-1037 AD). Infect Dis Poverty 2014;3(1):7.

9. Quiambao BP, Dy-Tioco HZ, Dizon RM, Crisostomo ME, Teuwen $D E$. Rabies post-exposure prophylaxis with purified equine rabies immunoglobulin: one-year follow-up of patients with laboratory-confirmed category III rabies exposure in the Philippines. Vaccine 2009;27(51):7162-7166.

10. Gholami A, Fayaz A, Farahtaj F. Rabies in Iran: past, present and future. J Med Microbiol Infect Dis 2014;2(1):1-10.

11. World Health Organization. WHO guide for rabies pre and post exposure prophylaxis in humans; 2014 [cited 2017 May 20]. Available from: http://www.who.int/rabies/PEP_Prophylaxis_guideline_15_12_2014.pdf.

12. Sabouri Ghannad M, Roshanaei G, Rostampour F, Fallahi A. An epidemiologic study of animal bites in Ilam Province, Iran. Arch Iran Med 2012;15(6):356-360.

13. Iran Data Portal. Iran statistical yearbook: population; 2013 [cited 2017 May 20]. Available from: https://www.amar.org.ir/ Portals/1/yearbook/1391/2.pdf.

14. Joseph J, N S, Khan AM, Rajoura OP. Determinants of delay in initiating post-exposure prophylaxis for rabies prevention among animal bite cases: hospital based study. Vaccine 2013; 32(1):74-77

15. Jha S, Khan WS, Siddiqui NA. Mammalian bite injuries to the hand and their management. Open Orthop J 2014;8(Suppl 1):194-198.

16. Kassiri H, Kassiri A, Mosavi R, Jashireh A, Lotfi M. Prevalence rate and epidemiological determinants of animal bite in Ahvaz County, Khuzestan Province, Southwestern Iran. J Acute Dis 2014;3(1):51-55.

17. Dadypour M, Salahi R, Ghezelsofla F. Epidemiological survey of animal bites in Kalaleh district, North of Iran (2003-05). J 
Gorgan Univ Med Sci 2009;11(1):pe76-pe79 (Persian).

18. Matter HC, Sentinella Arbeitsgemeinschaft. The epidemiology of bite and scratch injuries by vertebrate animals in Switzerland. Eur J Epidemiol 1998;14(5):483-490.

19. Khazaei S, Rezaeian S, Soheylizad M, Gholamaliee B. Factors associated with delay in post-exposure prophylaxis in bitten people. Med J Islam Repub Iran 2014;28:158.

20. Gautret P, Le Roux S, Faucher B, Gaudart J, Brouqui P, Parola P. Epidemiology of urban dog-related injuries requiring rabies post-exposure prophylaxis in Marseille, France. Int J Infect Dis 2013;17(3):e164-e167.

21. Pandey P, Shlim DR, Cave W, Springer MF. Risk of possible exposure to rabies among tourists and foreign residents in $\mathrm{Ne}$ pal. J Travel Med 2002;9(3):127-131.

22. Lyu C, Jewell MP, Piron J, Ehnert K, Beeler E, Swanson A, et al. Burden of bites by dogs and other animals in Los Angeles County, California, 2009-2011. Public Health Rep 2016;131(6): 800-808.

23. Kassiri H, Kassiri A, Lotfi M, Shahkarami B, Hosseini SS. Animal bite incidence in the County of Shush, Iran. J Acute Dis 2014;3(1):26-30.

24. Bahonar AR, Bokaee S, Khodaverdi KH, Nikbakht-Broogeni GhR, Rad MA. Epidemiology of rabies and animal biting in Ilam State. Iran J Epidemiol 2008;4(1):47-51 (Persian).

25. Majidpour A, Arshi S, Sadeghi H, Shamshirgaran S, Habibzadeh S. Animal bites: epidemiological considerations in Ardabil province, 2000. J Ardabil Univ Med Sci 2003;3(4):39-43 (Persian).

26. Poorolajal J, Babaee I, Yoosefi R, Farnoosh F. Animal bite and deficiencies in rabies post-exposure prophylaxis in Tehran, Iran. Arch Iran Med 2015;18(12):822-826.

27. Gongal G, Wright AE. Human rabies in the WHO southeast Asia region: forward steps for elimination. Adv Prev Med
2011;2011:383870.

28. Sheetal V, Kinnari G, Gneyaa B, Hemant T. Animal bite management practices: study at three municipal corporation hospitals of Ahmedabad. Natl J Community Med 2010;1(2):75-78.

29. World Health Organization. WHO expert consultation on rabies: first report. Geneva: World Health Organization; 2005, p. 2-10.

30. Verma R, Khanna P, Prinja S, Rajput M. Intra-dermal administration of rabies vaccines in developing countries: at an affordable cost. Hum Vaccin 2011;7(7):792-794.

31. Knobel DL, Cleaveland S, Coleman PG, Fèvre EM, Meltzer MI, Miranda ME, et al. Re-evaluating the burden of rabies in Africa and Asia. Bull World Health Organ 2005;83(5):360-368.

32. Sudarshan MK, Madhusudana SN, Mahendra BJ, Rao NS, Ashwath Narayana DH, Abdul Rahman S, et al. Assessing the burden of human rabies in India: results of a national multi-center epidemiological survey. Int J Infect Dis 2007;11(1):29-35.

33. Hampson K, Dobson A, Kaare M, Dushoff J, Magoto M, Sindoya $E$, et al. Rabies exposures, post-exposure prophylaxis and deaths in a region of endemic canine rabies. PLoS Negl Trop Dis 2008;2(11):e339.

34. Si H, Guo ZM, Hao YT, Liu YG, Zhang DM, Rao SQ, et al. Rabies trend in China (1990-2007) and post-exposure prophylaxis in the Guangdong province. BMC Infect Dis 2008;8:113.

35. Sengoz G, Yasar KK, Karabela SN, Yildirim F, Vardarman FT, Nazlican O. Evaluation of cases admitted to a center in Istanbul, Turkey in 2003 for rabies vaccination and three rabies cases followed up in the last 15 years. Jpn J Infect Dis 2006;59(4): 254-257.

36. Riahi M, Latifi A, Bakhtiyari M, Yavari P, Khezeli M, Hatami H, et al. Epidemiologic survey of animal bites and causes of delay in getting preventive treatment in Tabbas during 2005-2010. Tolooebehdasht 2012;11(1):20-31 (Persian). 